\title{
WHEN IS IT TOO SMALL TO BE BORN?
}

\author{
Kimera Lukanga Charles ${ }^{1 *}$, Linda N Lukolo ${ }^{2}$ \\ *IDepartment of Obstetrics \& Gynaecology, School of Medicine, University of Namibia \\ ${ }^{2}$ Department of Community and family, Medicine School of Medicine, University of Namibia
}

*Corresponding author: -

Email:lkimera@unam.na; kimerassuuna@gmail.com

\begin{abstract}
:
Low birth weight is the leading cause of perinatal and child mortality and contributes to several disabilities among survivors. It commonly results from preterm birth either with intact membranes or following preterm premature rupture of membranes. Proper knowledge of risk factors of low birth weight is important for identifying mothers at risk in order to properly plan and take appropriate actions before or immediately after delivery to prevent these poor outcomes. In this review paper, we looked at the subdivision of low birth weight, risk factors for preterm birth, consequences of low birth weight, threshold for viability as well as the interventions to reduce infant morbidity and mortality.
\end{abstract}

Key words: Born too small, too small to be born, low birthweight, preterm birth, intra-uterine growth restriction

\section{(c) $(\$)$}


Low birth weight (LBW) defines neonates who are born too small. WHO defines LBW as a birth weight of an infant of $2,499 \mathrm{~g}$ or less, regardless of gestational age. ${ }^{1}$ The low weight of a neonate may be due to either prematurity (preterm birth) or intra-uterine growth restriction (IUGR)/small for gestation (birthweight below the 10th percentile for gestational age) or both.

Table 1 below summarizes the subdivisions of low birth weight. According to WHO $16^{\text {th }}$ May 2019 news release, more than 20 million babies were born with a low birthweight in 2015.

Four different pathways result in preterm birth: ${ }^{2}$

- Precocious fetal endocrine activation

- Uterine over-distension. This may explain preterm delivery in multiple gestations and polyhydramnios

- Decidual bleeding. Decidual bleeding many times results from decidual separation, which this results in decidual activation and the resultant inflammatory reaction leading to prostaglandin production that in turn cause uterine contractions. This explains premature labour and delivery in cases of placenta abruption.

- Intrauterine inflammation/infection. Many times, there may be subclinical or clinical intrauterine infection and this is responsible for majority of preterm deliveries. This may relate to the women's socio-economic status, sexual and behavioral characteristics. In the tropics malaria infection contributes to significant number of preterm and low birth weights ${ }^{3}$.

There is increased risk of preeclampsia, eclampsia, obstetric cholestasis, twin gestation, anaemia, preterm labour, premature rupture of membranes, intrauterine foetal growth restriction, and intrauterine foetal death in adolescent pregnancies and increased risk of eclampsia, diabetes, and caesarean sections in advanced age pregnancies ${ }^{4}, 5$. The mean gestational age at delivery is 35 weeks for twins, 32 weeks for triplets and 29 weeks for quadruplets ${ }^{6}$.

The two main causes of LBW in Namibia are preterm pre-labour rupture of membranes (PPROM) and hypertensive conditions in pregnancy particularly pre-eclampsia and eclampsia. The child in the picture below was born of a 42 -yearold woman and that was the only risk factor found. The child however did was in the neonatal intensive care unit (NICU) and was weaned from NICU when she started sucking well on the mother's breast. In the United States PPROM is responsible for one-third of all preterm births each year and affects 120,000 pregnancies ${ }^{7}$.

Table 1: Summary of subdivision of low birthweight and prematurity

\begin{tabular}{|l|l|}
\hline Normal weight at term & Birth weight $2500-4200 \mathrm{~g}$ \\
\hline Vow birth weight & Birth weight $\leq 2499 \mathrm{~g}$ \\
\hline Extremely low birth weight & Birth weight $\leq 1499 \mathrm{~g}$ \\
\hline Preterm birth & Birth weight $999 \mathrm{~g}$ or less \\
\hline Late preterm births & $\begin{array}{l}28 \text { completed weeks or more } \\
\text { but less than } 37 \text { completed } \\
\text { weeks of gestation. }\end{array}$ \\
\hline Very preterm birth & 34 to 36 weeks' gestation \\
\hline Extreme immaturity & $28 \% 7$ weeks to 33\% $/ 7$ weeks \\
\hline
\end{tabular}

Risk factors for IUGR:

Maternal factors that increase the risk of LBW include:

- Infection during pregnancy

- Not gaining enough weight during pregnancy

- Previous pregnancy with a low-birth-weight baby

- Smoking

- Alcohol or drug use

- Age less than 17 or more than 35 years

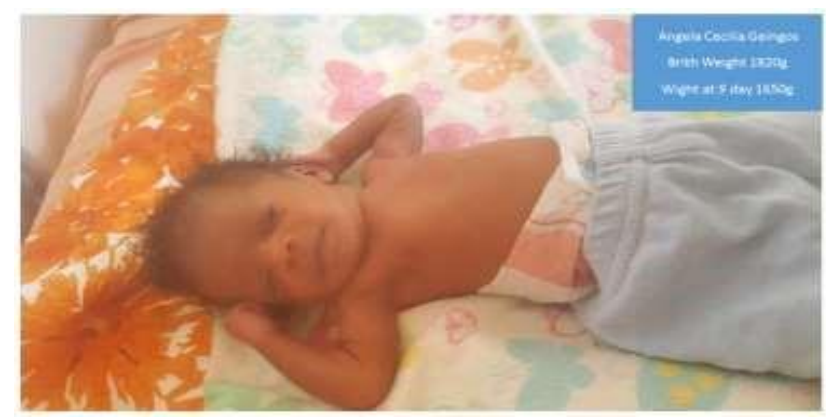

With kind permission from the mother 
Consequence of low birth weight (being born too small)

Most LBW result from being born preterm i.e. before 37 weeks of gestation. A low-birthweight baby may be healthy even though he or she is small. But a low-birth-weight baby can also have many serious health problems. Globally preterm birth remains a major health problem as the largest contributor to infant mortality. ${ }^{8}$ Varieties of morbidities, largely due to organ system immaturity, are significantly higher in infants born before 37 weeks' gestation compared with those delivered at term. Very low-birthweight and extremely low-birthweight infants predominantly suffer not only the immediate complications of prematurity but also long-term sequelae such as neurodevelopmental disability (see table 2). In our monthly maternal and perinatal reviews one of the paediatric consultants said "Almost no babies weighing less than $1 \mathrm{~kg}$ at birth in Windhoek Central and Katutura Hospitals survive". A baby weighing $1 \mathrm{~kg}$ is expected to be at an estimated gestation age of 28 weeks.

Table 2: Major Short- and Long-Term Problems in Very-Low-Birthweight infants

\begin{tabular}{|c|c|c|}
\hline Organ or System & Short-Term Problems & Long-Term Problems \\
\hline Pulmonary & $\begin{array}{l}\text { Respiratory distress syndrome, air leak, } \\
\text { bronchopulmonary dysplasia, apnea of } \\
\text { prematurity }\end{array}$ & $\begin{array}{l}\text { Bronchopulmonary dysplasia, } \\
\text { reactive airway disease, asthma }\end{array}$ \\
\hline $\begin{array}{l}\text { Gastrointestinal or } \\
\text { nutritional }\end{array}$ & $\begin{array}{l}\text { Hyperbilirubinemia, feeding } \\
\text { intolerance, necrotizing enterocolitis, } \\
\text { growth failure }\end{array}$ & $\begin{array}{l}\text { Failure to thrive, short-bowel } \\
\text { syndrome, cholestasis }\end{array}$ \\
\hline Immunological & $\begin{array}{l}\text { Hospital-acquired infection, immune } \\
\text { deficiency, perinatal infection }\end{array}$ & $\begin{array}{l}\text { Respiratory syncytial virus } \\
\text { infection, bronchiolitis }\end{array}$ \\
\hline $\begin{array}{l}\text { Central nervous } \\
\text { system }\end{array}$ & $\begin{array}{l}\text { Intraventricular haemorrhage, } \\
\text { periventricular leukomalacia, } \\
\text { hydrocephalus }\end{array}$ & $\begin{array}{l}\text { Cerebral palsy, hydrocephalus, } \\
\text { cerebral atrophy, } \\
\text { neurodevelopmental delay, } \\
\text { hearing loss }\end{array}$ \\
\hline Ophthalmological & Retinopathy of prematurity & $\begin{array}{l}\text { Blindness, retinal detachment, } \\
\text { myopia, strabismus }\end{array}$ \\
\hline Cardiovascular & $\begin{array}{l}\text { Hypotension, patent ductus arteriosus, } \\
\text { pulmonary hypertension }\end{array}$ & $\begin{array}{l}\text { Pulmonary hypertension, } \\
\text { hypertension in adulthood }\end{array}$ \\
\hline Renal & $\begin{array}{l}\text { Water and electrolyte imbalance, acid- } \\
\text { base disturbances }\end{array}$ & Hypertension in adulthood \\
\hline Haematological & $\begin{array}{l}\text { Iatrogenic anaemia, need for frequent } \\
\text { transfusions, anaemia of prematurity }\end{array}$ & \\
\hline Endocrinological & $\begin{array}{l}\text { Hypoglycaemia, transiently low } \\
\text { thyroxine levels, cortisol deficiency }\end{array}$ & $\begin{array}{l}\text { Impaired glucose regulation, } \\
\text { increased insulin resistance }\end{array}$ \\
\hline
\end{tabular}

Adapted from Williams Obstetrics $23^{\text {rd }}$ edition

In another related meeting one of the medical officers reported a child who was born with a birth weight of 650g (approx. 25-26 weeks), survived, and was at the time of reporting aged 5 years. Before celebrating the hospital's NICU success, we inquired about the developmental milestones of this child. He said the child could not crawl, could not speak and could not feed himself. Therefore, in addition to the exorbitant cost of care (most extremely preterm babies spend months in the hospital) these neonates receive while they are in NICU, families with such children encounter a big cost during taking care of these children due to the life-long disabilities these children often get. Many will need ongoing, specialized medical care and when they reach school age, they may need special schools or teachers to help with any learning problems. A follow-up on extremely low birth babies in the UK and North America indicated that very low birth weight $20 \%$ require special education, $25 \%$ function at a grade below expected and a further 30\% need special classroom assistance ${ }^{9}$. A 2006 report from the Institute of Medicine estimated the annual cost of preterm birth in the United States to be $\$ 26.2$ billion or more than $\$ 51,000$ per premature infant. ${ }^{10}$

\section{Threshold for viability:}

The duration of pregnancy is counted in weeks of gestation from the first day of the last menstrual period. A normal pregnancy lasts 40 weeks and pregnancy is term from 37 completed weeks to $41 \% / 7$ week (41 weeks and 6 days). From $37 \%$ to $38 \%$ weeks, the pregnancy is early term, full term is from $39 \%$ to $40 \%$ weeks, and late term is $41 \%$ to $41 \%$ weeks. Pregnancy is post term if it is $42 \%$ and beyond. A baby born before 37 weeks is considered preterm and, as shown in table 1 , extreme preterm is less than 28 completed weeks, very preterm is $28 \% 7$ to $33 \%$ and late preterm is $34 \%$ to $36 \%$ weeks.

Majority if foetuses have their lungs matured after 34 completed weeks. For pregnancies between $28 \%$ to 33 completed weeks, corticosteroids need to be administered to the mother to mature foetal lungs and other organs if delivery is anticipated (see Interventions to reduce infant morbidity and mortality of preterm births below). For Namibia and most African countries, the threshold for viability is $28 \%$ weeks of gestation. The period between $26 \%$ to $27 \%$ weeks is a grey area where the survival of neonate born during this period is doubtable.

Among the extremely premature neonates only less than $44 \%$ survive to discharge time and only about $8 \%$ of the survivors live without disability ${ }^{11},{ }^{12}$. Infants born before 26 weeks of gestation are described as fragile and vulnerable because of 
their immature organ systems. ${ }^{13}$ They are at high risk for brain injury from hypoxic-ischemia injury and sepsis. Hypoxia and sepsis start a cascade of events that lead to brain haemorrhage, white-matter injury that causes periventricular leukomalacia, and poor subsequent brain growth leading to neurodevelopmental impairment. For these extremely low birthweight neonates, one may consider deciding not to start resuscitation in the best interest of the baby. ${ }^{14}$ However the decision to resuscitate or not should be made by both the health care professional and the parents after thorough explanation of the possible outcome and prognosis. Many times, however the parents are not involved in making this important decision only to be overwhelmed by the outcome in future ${ }^{15}$. It is important to uphold the woman's culture, values, and religion during decision-making.

\section{Interventions to reduce infant morbidity and mortality of preterm births}

Interventions can be directed at all women for primary prevention and reduction of the risk of preterm birth (e.g., smoking cessation) or used to minimize the risk in pregnant women with known risk factors (e.g., cervical cerclage for incompetent cervix). Smoking cessation programs in pregnancy not only reduce the proportion of women who continue to smoke, but also reduce low birthweight and preterm birth (Cochrane review conclusion) ${ }^{16}$. However, the most beneficial set of maternal interventions are those that could improve survival chances and health outcomes of preterm infants when preterm birth is inevitable. These interventions are provided to the mother shortly before or during the birth process with the aim of overcoming immediate and future health challenges of the preterm infant, such as lung immaturity, susceptibility to infection, and neurological complications. The following considerations should be given to women in preterm labour:

1. One must confirm that the mother is in preterm labour

2. For pregnancies at 34 weeks or beyond, women with preterm labour should just be monitored for labour progression and foetal well-being. For active labour, an antimicrobial is given for prevention of neonatal group B streptococcal infection.

3. For pregnancies less than 34 weeks in women with no maternal or foetal indications for delivery, close observation with monitoring of uterine contractions and foetal heart rate is appropriate. Serial examinations are done to assess cervical changes

4. For pregnancies less than 34 weeks, administer corticosteroids to women with preterm labour to enhance foetal lung maturation provided there is no evidence of chorioamnionitis. Either intramuscular (IM) dexamethasone or IM betamethasone (total $24 \mathrm{mg}$ in divided doses) should be given to those with PPROM or preterm labour with intact membranes. A single repeat course of antenatal corticosteroid is recommended if preterm birth does not occur within 7-14 days after the initial dose, and a subsequent clinical assessment demonstrates that there is a high risk of preterm birth in the next 7 days ${ }^{17}$. Since treatment with corticosteroids for less than 24 hours is still associated with significant reductions in neonatal morbidity and mortality, a first dose of antenatal corticosteroids should be administered even if the ability to give the second dose is unlikely, based on the clinical scenario.

5. Maternal magnesium sulfate infusion for 12 to 24 hours should be considered to afford foetal neuroprotection for women at risk of imminent preterm birth before 32 weeks of gestation. Randomised clinical trials have shown that very-low-birthweight neonates whose mothers were treated with magnesium sulfate for preterm labour or preeclampsia were found to have a reduced incidence of cerebral palsy at 3 years.

6. Tocolysis: For pregnancies less than 34 weeks in women who are not in advanced labour, it may be reasonable to attempt inhibition of contractions to delay delivery while the women are getting corticosteroid therapy and group B streptococcal prophylaxis or even to enable transportation to a tertiary facility. After the course of corticosteroid is complete, tocolysis is not recommended when a mother with PPROM goes into labour.

7. Antibiotic prophylaxis: Prophylaxis against group B streptococcal infection to the neonate is an undisputed practice among women with preterm pre-labour rupture of membranes (PPROM). The recommended antibiotic of choice for prophylaxis in women with PPROM is erythromycin. The use of a combination of amoxicillin and clavulanic acid ("co-amoxiclav" or "augmentin") is not recommended as it may cause neonatal necrotizing enterocolitis (NEC).

8. Mode of delivery: Routine delivery by caesarean section for the purpose of improving preterm newborn outcomes is not recommended, regardless of cephalic or breech presentation (WHO). Caesarean section does not improve the outcome, yet it increases the risk of complications in future pregnancies e.g. if classical caesarean section has to be performed. Caesarean section therefore only becomes necessary for maternal indications and the parents should be made aware of this.

\section{References:}

[1].P07 - Disorders related to short gestation and low birth weight in ICD-10

[2].Simhan HN, Caritis SN (2007). "Prevention of Preterm Delivery". New England Journal of Medicine. 357 (5): $477-$ 487. doi:10.1056/NEJMra050435. PMID 17671256.

[3].Kimera Lukanga Charles; A Randomized Clinical Trial Comparing Artesunate/Amodiaquine And Coartem In Treatment Of Uncomplicated Malaria In Pregnancy In Mulago Hospital; Journal of Advance Research in Medical \& Health Science ISSN: 2208-2425

[4].Manju Lata Verma, Sabuhi Qureshi, Uma Singh, Nisha Singh, Pushpa Lata Sankhwar: Complications and Outcome of Pregnancy in Extremes of Reproductive Age Groups: Experience at Tertiary Care Center

[5].Londero, A.P., Rossetti, E., Pittini, C. et al. Maternal age and the risk of adverse pregnancy outcomes: a retrospective cohort study. BMC Pregnancy Childbirth 19, 261 (2019). https://doi.org/10.1186/s12884-019-2400-X

[6].Asha J Heard: Multifetal Pregnancy - Medscape (eMedicine); emedicine.medscape.com > article > 1618038-overview 
[7].Simhan HN; Canavan TP; Preterm premature rupture of membranes: diagnosis, evaluation and management strategies. BJOG. 2005; 112 Suppl 1:32-7 (ISSN: 1470-0328)

[8].Williams Obstetrics, $23^{\text {rd }}$ edition; Chapter 36. Preterm Birth

[9].Penny McParland a, Griff Jonesb, David Taylora; Preterm labour and prematurity; Current Obstetrics \& Gynaecology (2004) 14, 309-319

[10]. Management of Preterm Labor; Practice Bulletin No. 171: Obstetrics \& Gynecology: October 2016 - Volume 128 Issue 4 - $\mathrm{p}$ e5-e4 doi

[11]. Marlow N, Wolke D, Bracewell MA, Samara M. neurologic and developmental disability at six years of age after extremely preterm birth. N Engl J Med 2005;352;9-19.

[12]. Jerold F Lucey, Cherise A. Rowan, Patricia Shiono, et al; The fate of 4172 infants with birth weight of 401 to 500 Grams, the Vermont Oxford Network Experience (1996 - 2000); Paediatrics v.113, no. 6, June 2004, P1559 - 1566

[13]. Betty R. Vohr, Marilee Allen: Extreme Prematurity -The Continuing Dilemma.

[14]. Wilkinson AR, Ahluwalia J, Cole A, Crawford D, Fyle J, Gordon A, et al. Management of babies born extremely preterm at less than 26 weeks of gestation: a framework for clinical practice at the time of birth. Arch Dis Child Fetal Neonatal Ed 2009;94:F2-5. 